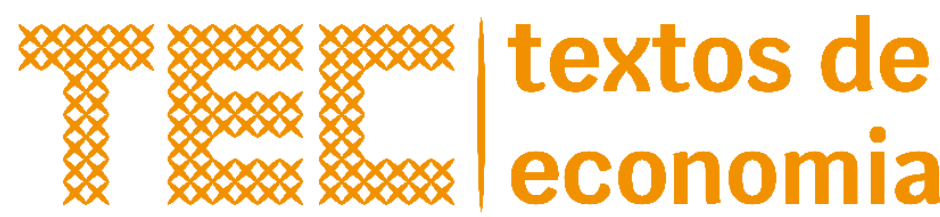

\title{
O RESGATE DO INSTITUCIONALISMO DE VEBLEN E SEUS AVANÇOS EM RELAÇÃO ÀS ABORdAGENS DE CHANG E NORTH
}

The rescue of Veblen's institutionalism and its advances in relation to Chang and North's approaches

Tales Rabelo Freitas

Universidade Federal do Rio Grande do Sul, Porto Alegre- RS, Brasil tales.rabelo@hotmail.com

\begin{abstract}
RESUMO
Para os institucionalistas, as instituições são fundamentais na interpretação do sistema econômico e para a proposição de políticas. As modernas abordagens de Chang e North apresentam distinções tanto na teoria quanto no receituário sobre as formas institucionais ideais para o desenvolvimento econômico e social das nações. Entretanto, a partir dos escritos de Veblen, o pai da escola institucionalista, é possível identificar lacunas nestas abordagens modernas. O objetivo deste trabalho é, portanto, mostrar que o resgate da teoria dos instintos, além de fornecer as bases para uma teoria institucionalista não teleológica, contrapõe tanto o individualismo metodológico da NEI quanto o reducionismo institucional da EPI.
\end{abstract}

PALAVRAS-CHAVE: Institucionalismo, desenvolvimento econômico, instituições, hábitos, instintos.

\begin{abstract}
For institutionalists, institutions are fundamental in interpreting the economic system and in proposing policies. Chang and North's modern approaches show distinctions in both theory and prescription on the ideal institutional forms for the economic and social development of nations. However, from the writings of Veblen, the father of the institutionalist school, it is possible to identify gaps in these modern approaches. The objective of this paper is, therefore, to show that the rescue of the theory of instincts, in addition to providing the basis for a non-teleological institutionalist theory, opposes both the methodological individualism of the NEI and the institutional reductionism of the EPI.
\end{abstract}

KEYWORDS: Institutionalism, development economic, institutions, habits, instincts.

Classificação JEL: B15

Recebido em: 01-06-2020. Aceito em: 15-07-2020. 


\section{INTRODUÇÃO}

As abordagens institucionalistas buscam nas instituições a explicação fundamental para as distintas trajetórias de desenvolvimento que se verificam entre os países. Autores como Ha-Joon Chang (2004a), Geoffrey Hodgson (1998), Douglass North (1990) entre outros, utilizam das instituições para analisarem o funcionamento da sociedade como um todo. Embora tenham em comum o uso das instituições, as abordagens derivadas destes autores divergem quanto à dinâmica existente entre indivíduo e instituições.

$\mathrm{Na}$ abordagem da Economia Política Institucionalista (EPI) de Chang, o curso histórico particular do desenvolvimento de cada nação cria uma economia política com uma estrutura institucional distinta para governar os mercados de trabalho, de capital, de bens e a propriedade (ZYSMAN, 1994). Essa estrutura institucional nacional molda a dinâmica da economia política, fornece um parâmetro para o sistema e estabelece limites dentro dos quais as políticas governamentais e as estratégias corporativas são escolhidas. Ou seja, a estrutura institucional induz certos tipos de comportamento corporativo e governamental que restringem e estabelecem uma lógica específica para o mercado e para o processo de formulação de políticas que são específicas dessa economia política.

Do lado oposto, a Nova Economia Institucional (NEI), liderada por North, dá uma fraca ênfase nos processos de condicionamento institucional, e se concentra no surgimento de instituições a partir de interações entre indivíduos dados (HODGSON, 1998). Aqui os agentes são concebidos pelo mesmo método hedonista da economia neoclássica, tendo apenas alguns pressupostos flexibilizados, como é o caso da alternância da racionalidade plena pela racionalidade limitada e da maior presença do viés oportunista evocado pela incompletude dos contratos que intermediam as transações. É a partir desta visão da natureza humana que surgem as instituições, cujo papel é "diminuir" as incertezas presentes sistêmicas e permitir a diminuição dos custos de transação que incorrem nas relações econômicas da sociedade.

Assim, enquanto a EPI dá primazia às instituições e, indiretamente, incorre no reducionismo institucional, cujo equívoco foi alertado por Veblen em seus textos, a NEI parte do indivíduo para explicar as instituições, abarcando o individualismo metodológico neoclássico. Desta forma, ambas as correntes se encontram em dissonância com o precursor do institucionalismo. De um lado, a abordagem vebleniana considera que o comportamento econômico e os mercados não são movidos por uma racionalidade objetiva, mas sim por um conjunto de hábitos mentais enraizados socialmente. Por outro, afirma-se 
que as inclinações humanas, inatas e afloradas pela experiência no ambiente social e material, direcionam os objetivos a serem perseguidos pelas instituições. Desta forma, indivíduos e instituições formam um todo inseparável, no qual a explicação para os fenômenos sociais não pode ser redutível a nenhum dos dois componentes. Mesmo que considerem as instituições como fruto das interações sociais, negligenciar uma análise mais profunda da natureza humana pode resultar no problema de reducionismo institucional (HODGSON, 2004). Para Veblen, as instituições também devem ser explicadas, uma vez que se pressupõe que elas não surgem num vácuo. Considerando que estas respondem aos imperativos da natureza humana, a compreensão das propensões existentes na mente dos agentes é fundamental para avaliar os limites e possibilidades para a atuação das instituições.

Para isto, este paper se divide em quatro seções principais, além desta introdução. A segunda abrangerá o debate entre as abordagens institucionalistas de North e Chang, em especial apresentando como fundo o tema do desenvolvimento. Já a terceira seção, que se subdivide em duas, abarca as especificidades da teoria vebleniana e suas convergências e divergências com as abordagens da NEI e da EPI, em especial no que tange sobre o tratamento da natureza humana. Por fim, conclui-se o trabalho.

\section{INSTITUIÇÕES E DESENVOLVIMENTO: AS ABORDAGENS DE NORTH E CHANG}

No final do século XX o papel das instituições na análise econômica passou a ganhar destaque nas discussões sobre desenvolvimento econômico. Para Chang (2004a), os institucionalistas visam explicar o sucesso ou o fracasso do processo de desenvolvimento de um país como resultado do arranjo institucional. Neste caso, a ênfase recai sobre o papel dos Estados na formatação de políticas com o intuito de incentivar ou restringir certos comportamentos dos agentes. Além disso, também reconhecem a importância das instituições não-estatais, como as organizações corporativas, sindicatos e a cultura.

O conceito de instituição é bastante amplo entre as abordagens institucionalistas. Essas são tratadas como regras do jogo, organizações ou hábitos sociais que condicionam o comportamento dos agentes econômicos (CONCEIÇÃO, 2000). Em termos gerais, podemos separar o Institucionalismo em três correntes distintas: 1) os Velhos Institucionalistas; 2) a Nova Economia Institucional (NEI); 3) e os Neo-Institucionalistas. Cada uma destas três abordagens analisam o sistema econômico no âmbito das 
instituições que o compõem. Entretanto, a distinção no conceito de instituição, que decorre das interpretações teóricas específicas, faz com que estas correntes nem sempre sejam convergentes. A princípio podemos classificar a NEI como a mais discrepante da abordagem original dos velhos institucionalistas, enquanto a corrente dos neoinstitucionalistas é derivada diretamente das ideias de Veblen.

A corrente dos velhos institucionalistas, dominantemente ocupada por Veblen e John R. Commons, não é formada por um corpo teórico homogêneo e totalmente convergente. O ponto comum destes dois autores é a importância das instituições no direcionamento da ação humana, pois o argumento é que o indivíduo não deve ser considerado como dado. Desta forma, rejeita-se o uso comum de funções de preferências pré-estabelecidas que modelam o comportamento e o pensamento dos agentes (HODGSON, 1998).

Contudo, ambos apresentam distinções no conceito de instituição, o que servirá de base para outros autores na formação de correntes teóricas heterogêneas. Enquanto Veblen concebe as instituições como hábitos mentais enraizados socialmente que estabelecem formas de pensamento ou ação de certa prevalência, Commons leva a definição mais para o lado das questões jurídicas, deixando de lado os fatores culturais (HODGSON, 2003) ${ }^{1}$. Neste caso, Veblen é associado aos neo-institucionalistas, como Hodgson, enquanto as ideias de Commons alicerçam a análise da NEI, de North e Williamson.

Avançando sobre o entendimento das instituições pelas modernas abordagens institucionalistas, tem-se que os autores da NEl as interpretam como sendo um conjunto de restrições criadas pelos humanos que modelam sua interação, ou mais popularmente conhecidas como "as regras do jogo". Nesta corrente de pensamento, o foco recai sobre as organizações e as entidades sociais sistemáticas e integradas como dinheiro, linguagem e lei (HODGSON, 1998, 2003). Já os neo-institucionalistas apresentam uma compreensão mais ampla das instituições, destacando não apenas suas capacidades de restringir comportamentos, mas também habilitar e constituir visões de mundo.

Esta amplitude e distinção do conceito de instituição entre as escolas institucionalistas está relacionada à multiplicidade de interpretações sobre o papel que este componente apresenta no desenvolvimento. Sobre este tema, a NEI - de Douglass North e Oliver Williamson - e a EPI - de Ha-Joon Chang e Peter Evans - rivalizam entre si. Embora os

\footnotetext{
${ }^{1}$ Apesar de Commons ter dado mais ênfase à noção de instituição como regras jurídicas que regulam a ação social, o autor menciona a ideia de "costume" em Legal Foundations (COMMONS. 1924).
} 
autores deste último grupo não sejam considerados genuinamente institucionalistas, pois não fazem referências aos expoentes desta corrente, suas ideias são, em certa medida, análogas às de Veblen e dos neo-institucionalistas. (CAMPOS, 2016). Pode-se dizer que a diferença principal entre os autores da EPI e dos neo-institucionalistas está no foco dos temas tratados. Enquanto os primeiros se concentram em questões sobre política econômica e no arcabouço institucional para a promoção do desenvolvimento nos países de industrialização tardia, os últimos especificam as bases epistemológicas para um programa institucionalista contemporâneo (JAMESON, 2006). Talvez a maior semelhança fique por conta dos argumentos utilizados para contrapor a NEI, os quais serão tratados mais à frente.

Apesar da NEI e a EPI serem rivais no debate institucionalista, ambas apoiam o argumento de que as instituições importam e têm a primazia na explicação das trajetórias de desenvolvimento dos países. Mas as semelhanças terminam por aí, pois as análises da dinâmica das instituições e seus efeitos na sociedade são diferentes entre estas abordagens. Em termos gerais, a EPI surge no debate como alternativa ao receituário da NEI. Afirma-se que esta última endossa o paradigma neoliberal ao pregar o sistema de livre mercado como instituição central e que baliza a dinâmica das demais instituições sociais. Já a EPI se encontra em linha com o receituário heterodoxo, mais especificamente argumentando que não há um determinismo institucional que promoveria os mecanismos necessários para a promoção do desenvolvimento desejado pelos países.

\subsection{Instituições na perspectiva da Nova Economia Institucional}

O trabalho de Williamson (2000) é um dos principais referenciais utilizados para compreender a natureza das instituições pela perspectiva da NEI. Neste, o autor analisa quatro níveis do aspecto social em que as instituições operam e sobre as quais a NEl concentra sua análise econômica. Os quatro níveis de análise são postados de acordo com o que se entende ser a ordem hierárquica definitiva entre eles. No caso, os níveis mais elevados impõem restrições aos níveis mais baixos.

No nível mais alto, ou seja, o nível um está o enraizamento social. É neste nível onde as normas, os costumes, a cultura e as tradições estão localizados. Apesar deste nível de análise ser de fundamental importância para a análise do institucionalismo vebleniano, este é assumido como dado pelos economistas da NEI. Isso porque se argumenta que as instituições neste nível mudam muito lentamente, da ordem de centenas a milhares de anos. 
Já o nível dois se refere ao ambiente institucional que regulamenta as regras formais da sociedade. Nele estão incluídas a constituição, as leis e os direitos de propriedade. É neste nível que Williamson (2000) chama de "primeira ordem de economização", que se entende como um dos pontos de partida para a análise econômica da NEI: onde as regras formais do jogo se formam. Essas regras do jogo, por sua vez, são fundamentais para restringir o componente do comportamento humano que é fonte de instabilidade e do caos econômico e social.

O ambiente institucional do nível dois é construído a partir das restrições impostas pelos costumes e tradições instituídos historicamente. As instituições do nível dois incluem a estrutura governamental e suas funções burocráticas. As mudanças neste nível ocorrem em um período bem menor do que no anterior, abrangendo um intervalo de 10 a 100 anos.

Em seguida, vem o nível três, que é onde estão localizadas as instituições de governança. É neste nível que se observa a unidade da atividade econômica em última instância: a transação. A transação que é, por sua vez, a unidade básica da análise econômica na abordagem da Teoria dos Custos de Transação, iniciada a partir dos trabalhos de Coase (1992), e estendida pelo próprio Williamson (2000).

A estrutura de governança presente no nível três se refere ao esforço de orquestrar a ordem, mitigar os conflitos entre os agentes e produzir ganhos que sejam desejáveis por ambos os lados que realizam as transações econômicas. Assim, a governança formata os incentivos econômicos e as restrições para ações que inviabilizam a eficiência. Williamson (2000) chama este nível de "segunda ordem de economização", e aponta que a reorganização das transações entre estruturas de governança, como organizações corporativas e mercados, se transformam numa ordem de um a dez anos, cujo propósito principal é alcançar estruturas de governança cada vez mais eficientes.

Por fim, tem-se o nível quatro, que é aquele em que a economia neoclássica opera. Aqui é onde o aparato de otimização é empregado, e a firma é tipicamente descrita como uma função de produção. Neste nível, os ajustes de preços e produção ocorrem praticamente de forma contínua, sendo chamado por Williamson (2000) de "terceira ordem de economização".

Em termos gerais, para Williamson (2000), a NEI se concentra nos níveis dois e três, cujas restrições determinadas pelos níveis institucionais ali estabelecidas ditam a dinâmica com que as firmas se adaptam e, consequentemente, determina o nível de eficiência da produção. 
Assim sendo, como já afirmado anteriormente, a NEl, foca na capacidade das instituições de restringir comportamentos humanos. Para North (1990) isto se deve pelo pressuposto de que os indivíduos não conseguem agir de forma perfeita, como previsto pelos modelos da economia neoclássica, pois os agentes apresentam racionalidade limitada e informação incompleta. Aliado a isto, o comportamento egoísta dos seres humanos impede que as interações ocorram sem custos elevados. Assim, as instituições emergem como mecanismos de restrição que os indivíduos se autoimpõem para estruturar as relações, incorrendo em menores custos de transação e também diminuindo as incertezas sistêmicas.

Para North (1990) as instituições estão presentes na sociedade em distintas formas. Podem se apresentar de modo formal e revelado, como as leis, ou informal e intrínseco, a partir da cultura e dos valores morais. Estes tipos institucionais diferem basicamente quanto à sua dinâmica de mudança. Em linha com o autor, as regras formais podem mudar rapidamente em função de decisões políticas ou judiciais, enquanto as instituições informais não são passíveis de mudança deliberada, cuja transformação ocorre em passos lentos, de forma incremental e incerta.

Em North $(1990,1994)$ as instituições, que são as regras do jogo, mudam a partir da interação dos agentes com as organizações, as quais representam os jogadores. Nas palavras do autor, "as instituições, juntamente com os condicionantes convencionais concebidos pela teoria econômica, determinam as oportunidades em uma sociedade. Organizações são criadas para aproveitarem essas oportunidades e, à medida que evoluem, alteram as instituições." (NORTH, 1990, p. 20). A trajetória da mudança institucional é, portanto, consequência do feedback que os indivíduos dão à estrutura institucional vigente em cada período, uma vez que estes se organizam para reagir às oportunidades criadas.

Por conseguinte, North (1994) afirma que as melhores organizações surgem em contextos institucionais que permitem a adaptação das melhores práticas. "That is, if the institutional framework rewards piracy then piratical organizations will come into existence; and if the institutional framework rewards productive activities then organizations- firms-will come into existence to engage in productive activities." (NORTH, 1994, p. 361).

Diante disto, a receita para o aumento da produtividade e do crescimento econômico para os países pobres é a modificação das instituições, de modo que seja possível reduzir os custos de transação e permitir o surgimento de boas organizações. Conforme North (2005), os custos de transação são derivados essencialmente de quatro fatores: 1) 
mensuração das múltiplas dimensões avaliáveis dos bens e serviços; 2) proteção de propriedades individuais; 3) integração do conhecimento disperso de uma sociedade e 4) cumprimento dos contratos firmados. Assim, para melhorar a performance econômica, é necessário a criação de instituições que visem a diminuição destes custos. No caso, sugere-se: 1) o desenvolvimento de um sistema uniforme de pesos e medidas (um sistema de preços autorregulável); 2) o melhoramento das especificações de direito de propriedade; 3) a criação de um sistema judicial efetivo para reduzir os custos de execução dos contratos e 4) o desenvolvimento de instituições para integrar o conhecimento disperso da sociedade, bem como monitorar e avaliar acordos e julgar disputas. Além disso, o autor também se mostra contra o uso demasiado da política para a resolução dos problemas, por considerar esta como a principal fonte do aumento dos custos de transação, uma vez que "political markets reflect imperfect knowledge between principals and agents" (NORTH, 2005, p. 79).

Em um primeiro momento, o autor tenta se esquivar da tarefa de recomendar um receituário institucional que se encontra em linha com a visão neoliberal e inspirado no pensamento dominante ocidental. Nas palavras de North (2005, p. 159) "It should be emphasized that the institutions that have emerged in the Western world, such as property rights and judicial systems, do not have to be faithfully copied in developing countries." Entretanto, na mesma página o autor afirma que os países que quiserem manter um ritmo constante de crescimento e desenvolvimento, cedo ou tarde, terão que incorporar o sistema de incentivos "padrão" das sociedades ocidentais.

Para justificar esse argumento, North (2005) se apoia na incerteza derivada da natureza humana e da complexa interdependência entre instituições formais e informais. Para o autor, as instituições incorporam a intencionalidade dos indivíduos, de forma que a estrutura institucional é uma criação feita pelo homem, cujo funcionamento não é automático nem "natural". Em um mundo não ergódico, onde não é possível prever o comportamento futuro dos agentes e das organizações, e que não se sabe o resultado da imposição de instituições formais sobre uma estrutura cultural livre de controle tecnocrático, a melhor receita é a manutenção de instituições que permitem experimentos de tentativa e erro destes atores. Tal estrutura envolve não apenas uma variedade de instituições e organizações, de modo que políticas alternativas possam ser experimentadas, mas também meios efetivos de eliminar soluções malsucedidas.

Segundo North (2005), as instituições que garantem os menores custos de transação permitem que o processo de ajustamento das organizações resulte em ganhos de eficiência da economia. Entretanto, esta evolução levaria um período relativamente longo para que 
as instituições informais se adequarem à estrutura formal, não havendo atalhos para este processo. A mudança institucional ocorre quando os resultados da interação social não se aproximam do que os indivíduos intencionam. Nas palavras do autor, "Institutional change is the structural change humans impose on human interaction with the intention of producing certain outcomes" (NORTH, 2005, p. 78).

\subsection{Instituições à luz da abordagem da Economia Política Institucionalista}

É importante atentar para um ponto em comum na visão de North e de Chang. Para ambos, o fator humano e a existência de instituições informais fazem com que os efeitos da implementação de novas instituições formais sejam incertos. Não é um mero exercício tecnocrático, pois o sucesso de um arranjo institucional dependerá de como este se relaciona com a cultura e mentalidade dos agentes (CHANG, 2007). Para Chang (2007) as instituições podem apresentar múltiplas funções, impactando a sociedade de outras formas além do que foi programada. A incerteza no processo de construção institucional está atrelada ao fato de não existir relação simples entre uma forma institucional e uma função desejada.

Por outro lado, em contraposição à NEI, o autor foge do foco no conceito de instituições como restrições à interação humana, afirmando que uma análise restringida das funções das instituições muitas vezes negligencia as potencialidades que estas podem ter no desenvolvimento das sociedades e também gera sérias implicações para a maneira como as reformas institucionais são implementadas. O problema associado a este tipo de avaliação é chamado pelo autor de institutional monotasking. Um exemplo é o papel que os economistas do mainstream concebem para o Banco Central. Para Epstein (2006) há muitas funções que esta instituição pode desempenhar, indo além da busca pela estabilidade dos preços, como o apoio a indústrias manufatureiras e a promoção do setor financeiro ${ }^{2}$.

A EPI avança sobre a abordagem de North ao enfatizar as capacidades das instituições de habilitar certas ações e constituir visões de mundo. Compreende-se que para analisar o papel das instituições no processo de desenvolvimento econômico é

\footnotetext{
2 Epstein (2006, p. 97 - 98) resume o papel básico dos bancos centrais ao longo da história econômica: "(1) unifying and issuing the country's bank notes; (2) acting as the government's bank; (3) acting as the commercial banks' bank; (4) serving as a lender of last resort to the banking sector and possibly the whole financial system; (5) conducting monetary policy to manage the foreign exchanges and the price level; (6) conducting monetary policy to manage the overall level of economic activity and (7) allocating credit to promote national goals."
} 
essencial compreender a capacidade das regras formais e informais da interação social de condicionarem as ações e a visão de mundo dos agentes (CHANG \& EVANS, 2005).

Para esta abordagem, há três meios pelos quais as instituições moldam os indivíduos. O primeiro, e em linha com o pensamento da $\mathrm{NEI}$, é a capacidade de restringir comportamentos indesejados. As instituições também têm a competência de promover certas ações. Um exemplo de instituição que atua tanto restringindo quanto habilitando a conduta dos indivíduos é o direito de propriedade intelectual. Segundo Chang e Evans (2005, p. 4) "firms can engage in innovation more aggressively because there are intellectual property rights, which remove the fear that other agents will copy our ideas and usurp the gains that should accrue to us."

A terceira, e mais importante, é a capacidade constitutiva. Esta se refere à dimensão simbólica das instituições, concebendo os valores e visões de mundo dos indivíduos (CHANG, 2007). O que ocorre é que os indivíduos, na medida em que vão interagindo com as instituições, passam a internalizar em suas mentes os valores contidos nestas. Este prisma institucional é bastante negligenciado pelos economistas da NEI e da corrente neoliberal, mas é de grande valor para a abordagem teoria de autores como Veblen e Hodgson.

Além disso, as especificidades teóricas nos escritos destes autores, em especial no que tange o papel das instituições, também implicam em diferenças na interpretação da mudança econômica e, consequentemente, na proposição de política. Do lado de North (2005), o foco nas instituições como mecanismos de restrição leva à compreensão da evolução econômica como um processo não deliberado. Para este, a mudança institucional vem através das imposições que os agentes fazem sobre a própria interação, no intuito de produzir os resultados desejados. Tal processo de ajustamento não é deliberado porque é fruto de fatores relacionados à consciência humana, os quais não são passíveis de controle pelas instituições formais segundo a NEI. Já na abordagem da EPI, o foco no papel constitutivo das instituições permite a ideia de processos deliberados de mudança econômica (CAMPOS, 2016). Ao contrário da NEI, aqui a cultura é passível de sofrer rápidas transformações em função das mudanças verificadas nas demais instituições. $O$ processo de desenvolvimento econômico, para a EPI, é um processo de mudança institucional que muitas vezes é realizada de forma deliberada na qual se reconhece a consciência humana no processo de construção das instituições.

\subsubsection{Críticas da EPI ao receituário mainstream da NE}


O primeiro posicionamento de Chang em seus escritos é conter os argumentos da economia política neoclássica - representados nos trabalhos de Balassa et al (1982), Little (1982) e Lal (1983) - e da NEI. Estas abordagens criticam fortemente as ideias de que algumas atividades econômicas são socialmente mais desejáveis que outras, se opondo às políticas industriais seletivas e de restrição do comércio. Para Chang (2004b), as críticas são mais de cunho político do que de racionalidade econômica. O argumento é que o Estado é identificado como uma organização controlada por grupos políticos que se utilizam da instituição para realizar os próprios interesses, resultando em consequências indesejáveis do ponto de vista social.

Campos (2016) resume bem a proposta neoliberal, que possui dois componentes intimamente relacionados, um político e um econômico. O político consiste na necessidade de despolitização da política econômica. Já o componente econômico se refere às ideias de liberalização e desregulamentação dos mercados. De acordo com esta corrente, "os países em desenvolvimento deveriam especializar-se em produtos intensivos em mão de obra, e não em produtos intensivos em capital e tecnologia, como insistiam as políticas para promoção do desenvolvimento aplicadas nestes países" (p. 225). Além disso, a insistência nas políticas desenvolvimentistas geraria perdas e ineficiências em seus sistemas econômicos. A saída pela liberalização dos mercados reduziria as perdas e aumentaria a eficiência na alocação dos recursos.

O argumento de contraposição de Chang (1994) é de que os mercados falham no processo de alocar os recursos de forma eficiente. Além disso, o sistema de mercado autorregulável também não garante que a alocação de fatores será realizada nos setores desejados pela sociedade. Para isto, o autor faz uso do argumento moralista de merit goods e demerit goods. Os primeiros são aqueles bens e serviços que a sociedade deseja encorajar a produção, dado que, devido a preferências individuais do consumidor, podem ser sub-consumidos, como a educação e a saúde preventiva. Já o segundo se refere a situação inversa, ou seja, são bens que a sociedade deseja que a produção seja desencorajada, como drogas. Nestes casos, a ação estatal é desejada para direcionar o mercado no cumprimento dos interesses da sociedade.

Chang (2000) critica a chamada "suposição da primazia do mercado". Em linha com a abordagem dos custos de transação de North (1990) e Williamson (1975, p. 20), esta hipótese estabelece que os mecanismos de mercado formam o ponto de referência para a compreensão de qualquer fenômeno econômico. Na visão destes autores, "in the beginning there were markets", de forma que as demais instituições, como as firmas, o Estado e as 
organizações, derivam dos esforços que os agentes realizam para contornar as falhas de mercado. Portanto, a natureza das instituições sociais, pela perspectiva da NEI, é entendida através do prisma do mercado, sendo este o núcleo elementar que serve como ponto de referência final e abrangente da análise econômica.

Para Chang (2000) o mercado é uma instituição como outra qualquer e que, ao longo da história, emergiu de forma deliberada pelo Estado ${ }^{3}$. O autor cita o papel preponderante das intervenções do governo norte-americano na infraestrutura (especialmente ferrovias e telegramas), nas pesquisas agrícolas e na proteção da indústria infante no desenvolvimento do mercado. Também cita os exemplos do Reino Unido, França, Alemanha, Suécia, Áustria e dos países do Leste Asiático, que seguiram o modelo de Estado Desenvolvimentista para a promoção da indústria e dos mercados. O argumento geral é de que nenhum país atualmente desenvolvido e industrializado obteve tal status sem o envolvimento do governo.

A hipótese da primazia do mercado também abarca a ideia de que esta instituição é isenta de valores políticos. "One major assumption behind neo-liberal doctrine is the belief that politics allows 'sectional' interests to 'distort' the 'rationality' of the market system and therefore this is something that has to be purged from the market" (CHANG, 2000, p. 16). Porém, praticamente todos os preços têm algum componente político na sua formação. Conforme Chang (2000), o estabelecimento e distribuição de direitos de propriedade e outros direitos que definem as "dotações" que a economia neoclássica toma como dados é um exercício altamente político. Salários e taxas de juros, por exemplo, são dois tipos de preços fundamentalmente determinados por questões políticas.

Wages are affected not only by minimum wage legislation, but also by various regulations regarding labour standards, welfare entitlements, and most importantly immigration control. Interest rates are also highly political prices, despite the guise of "de-politicization" that those who support central bank independence want to give to the process of interest rates determination. The recent debate in Europe on the relationship between political sovereignty and autonomy in monetary policy, which was prompted by the approaching European Monetary Union, shows this very clearly. When we add to them those numerous regulations in the product markets regarding safety, pollution, import content, and so on, there is virtually no price which is "free from politics" (CHANG, 2000, p. 17).

\footnotetext{
${ }^{3}$ Chang (2000) compartilha do argumento de Polanyi (2012) ao enfatizar o papel determinante do Estado no processo de desenvolvimento dos mercados, o que contrapõe a visão do surgimento espontâneo desta instituição.
} 
Logo, a posição do autor é de rejeitar a hipótese neoclássica da supremacia do mercado e defender uma alternativa que incorpore a diversidade institucional presente nas sociedades. Para Chang (2000), o capitalismo é mais do que uma coleção de mercados, é também um sistema composto por uma ampla variedade de instituições. As firmas são concebidas como instituições responsáveis pela organização da produção, os mercados realizando as trocas, enquanto o Estado se encarrega de abordar os interesses políticos dos vários grupos que compõem a sociedade. A ideia de que o mercado é uma construção política rompe com a preocupação acerca de suas falhas, pois dizer que o mercado está falhando não significa que a economia como um todo esteja fracassando.

\section{AS LIMITAÇÕES DAS MODERNAS ABORDAGENS INSTITUCIONALISTAS À LUZ DOS ESCRITOS DE VEBLEN}

Diante dos aspectos gerais do institucionalismo da NEI e da EPI, o passo a seguir será um exercício de comparação entre estas abordagens e as contribuições de Veblen. Como visto, Chang e North apresentam receituários de política distintos, derivados principalmente da noção de instituição empregada em cada análise. Sobre isto, a partir de uma avaliação geral, é possível estabelecer uma maior aproximação de Veblen com os autores da EPI, uma vez que ambas as escolas utilizam um conceito igualmente amplo de instituição e se opõem a qualquer aproximação com a escola neoclássica. Entretanto, há questões em aberto sobre a compreensão da natureza humana na abordagem de Chang, visto que o autor não incorpora a ideia de instintos e deixa vaga seu entendimento de indivíduo. É sobre esta lacuna, e mais especificamente sobre quais implicações teóricas e práticas é possível verificar a partir da reincorporação da teoria vebleniana de natureza humana nesta abordagem institucionalista contemporânea, que se buscará avançar a partir de agora.

\subsection{As limitações do individualismo metodológico da NEI e suas distinções com o pensamento vebleniano}

Como visto no capítulo anterior, Veblen rejeitou a proposição de que os indivíduos são seres exclusivamente sociais, concebidos na análise econômica como meios de transmissão e expressão das leis e mudanças sociais (HODGSON, 2004). Ou seja, para o institucionalista norte-americano as instituições têm capacidade limitada na regulação da 
mentalidade humana. Vejamos como as ideias do autor se encaixam no debate corrente sobre instituições e desenvolvimento.

O primeiro ponto a ser abordado é sobre o conceito de instituições. Tem-se que a teoria de Veblen abarca a concepção de instituição tanto utilizada pela NEI quanto pela EPI. No primeiro caso, o autor expoente do institucionalismo trata as instituições como mecanismos de seleção atuando sobre hábitos mentais individuais, fazendo com que certos tipos de comportamentos se tornem indesejados e, portanto, restringidos na sociedade, enquanto aqueles considerados benéficos são habilitados e incentivados. Isso faz com que os indivíduos devam se adaptar ao tipo de mentalidade que é bem estimada dentro da sociedade.

Logo que determinada propensão ou determinado ponto de vista foram aceitos como padrão ou norma de vida autorizados, estes reagirão no caráter dos membros da sociedade que os aceitaram, e até certo ponto, modelarão seus hábitos mentais e exercerão uma vigilância seletiva no desenvolvimento das aptidões e das inclinações do homem. O efeito é em parte conseguido por uma adaptação educacional coercitiva dos hábitos de todos os indivíduos, em parte pela eliminação dos indivíduos inadaptados e sua descendência (VEBLEN, 1983, p. 97).

Em linha com a psicologia dos hábitos e instintos de William James (1890) e William Mc Dougall (1908), as instituições, em um nível de complexidade superior, atuam selecionando não apenas os hábitos de pensamento mais adequados à estrutura vigente, mas também as propensões instintivas que estejam em consonância com os objetivos que estas mesmas instituições permitem realizar. A estrutura institucional tem o poder de estabelecer o que é passível de boa estima e, portanto, deverá ser estimulado e restringido. Veblen $(1898,1987)$ mostrou como as formas habituais de emulação, estabelecidas de formas distintas ao longo do desenvolvimento das sociedades humanas, direcionaram os esforços dos indivíduos para ações que envolvessem ora o instinto para o artesanato, ora o instinto predatório.

O conceito de instituição em Veblen (1987) também engloba os mecanismos constitutivos. A todo o momento os agentes realizam o exercício de confrontar seus hábitos mentais individuais com aqueles de aceitação geral da sociedade. Vez ou outra estes padrões gerais de pensar e agir são contestados e levados à mudança, entretanto, a regra geral é a incorporação do senso comum nos hábitos individuais. 
Tal incorporação ocorre uma vez que os hábitos de pensamento formam uma categoria amplamente flexível, mais do que as propensões instintivas inatas. Enquanto a configuração instintiva responde às propriedades provenientes do nível biológico, os hábitos são facilmente concebidos e alterados a partir do contato com as instituições. Ou seja, a habituação é um processo derivado da coletividade, absorvendo o que é socialmente desejado e bem avaliado, ao passo que os instintos estão limitados às atividades fisiológicas. Nas palavras do autor "History teaches that men, taken collectively, learn by habituation rather than precept and reflection; particularly as touches those underlying principles of truth and validity on which the effectual scheme of law and custom finally rests" (VEBLEN, 1919). Sendo assim, as formas habituais de pensar e agir são passíveis de serem moldadas e constituídas pela estrutura social.

Embora os escritos de Veblen contenham conceitos abarcados pela NEl, os resultados analíticos derivados destes arcabouços são divergentes. Como avaliado por Conceição (2002), o conceito de instituição como processo de seleção e restrição implica em uma estrutura social totalmente mutável e flexível, enquanto para a NEI as instituições funcionam como mecanismos de otimização que levam ao equilíbrio.

Para Veblen e os neo-institucionalistas - incluindo também a corrente da EPI -, as instituições mudam e podem pressionar o sistema a partir de conflitos e crises. "Em qualquer sistema social há uma permanente tensão entre ruptura e regularidade, exigindo constante reavaliação de comportamentos rotinizados e decisões voláteis de outros agentes" (CONCEIÇÃO, 2002, p. 123). O caráter conflituoso e de não-equilíbrio das instituições se deve pelo argumento de que as instituições são o resultado de processos passados, adaptados a circunstâncias passadas, de modo que se requer uma contínua adaptação com as exigências do presente (VEBLEN, 1987).

Já para o lado da NEI, as instituições surgem para resolver os conflitos humanos, gerando ordem e equilíbrio ao sistema. A definição de instituições como sendo "as regras do jogo" tem inclusive despertado o interesse dos estudiosos de teoria dos jogos para a incorporação das instituições nos modelos ${ }^{4}$. Para Nelson (1995, p. 80), as instituições têm sido associadas teoricamente com soluções particulares de jogos com equilíbrio múltiplo de Nash, ou seja, "the pattern of behavior associated with an equilibrium is seen as 'institutionalized"'.

\footnotetext{
${ }^{4}$ Uma referência importante é o trabalho de Schotter (1981), que buscou adotar um programa que torna as instituições endógenas aos modelos neoclássicos, explicadas a partir da teoria dos jogos.
} 
Apesar das diferenças, tanto a NEI quanto os antigos e neo-institucionalistas utilizam um conceito amplo de instituição. Em todas estas correntes as instituições atuam habilitando e/ou restringindo comportamentos, além de constituir valores morais e visões de mundo na mente dos indivíduos - esta última capacidade é mais enfocada pelos antigos e neo-institucionalistas. Os mecanismos de atuação das instituições são definidos tanto pelos costumes rotineiros de um povo - instituições informais - quanto pela materialização dos valores culturais na forma de leis - instituições formais. O motivo dessa definição abrangente é que todas essas entidades envolvem características comuns, as quais são delineadas por Hodgson (1998):

- Todas as instituições envolvem a interação de agentes, com feedbacks cruciais;

- Todas as instituições têm várias características e conceitos e rotinas comuns;

- Instituições sustentam e são sustentadas por conceitos e expectativas compartilhadas;

- Embora não sejam nem imutáveis nem imortais, as instituições têm qualidades relativamente duráveis, auto reforçadas e persistentes;

- As instituições incorporam valores e processos de avaliação normativa. Em particular, as instituições reforçam sua própria legitimação moral: aquilo que resiste correta ou incorretamente - é geralmente visto como moralmente justo.

Em um primeiro momento, essa abrangência pode gerar certa repulsa entre os economistas na medida em que se argumenta que isto torna o conceito vago e, consequentemente, insuficiente para explicar os processos complexos existentes nos sistemas sociais. Para fugir das oposições deste tipo, a NEI se rende ao reducionismo proveniente do individualismo metodológico, no intuito de contrabalancear a amplitude do conceito de instituição. Isso faz com que esta corrente se aproxime do arcabouço neoclássico. Desta forma, as críticas acabam recaindo mais sobre as abordagens de cunho vebleniano.

Para Hodgson (1998) o desconforto de parte dos economistas com o institucionalismo de Veblen se deve pela falta de maior formalização do autor, via modelos matemáticos deterministas. Além disso, a caracterização do "antigo" institucionalismo como puramente descritivo ou anti-teórico não resiste a uma análise minuciosa, pois Veblen foi o primeiro cientista social a tentar desenvolver uma teoria de evolução econômica e institucional com linhas fundamentalmente Darwinianas. Em termos gerais, o institucionalismo vebleniano tem como identidade o desvio de qualquer tipo de determinismo, inclusive o institucional, de tal modo que se esta corrente tivesse uma teoria 
geral, seria uma teoria indicando como desenvolver uma análise variada e específica de fenômenos específicos (HODGSON, 1998).

A diferença crucial entre a NEI, a EPI e a visão de Veblen é a compreensão sobre a natureza humana. A começar pela $\mathrm{NEI}$, é reconhecido que esta não incorpora a noção de hábitos individuais, de modo que os indivíduos são dotados de capacidade cognitiva preestabelecida e imutável. A associação das instituições como fonte de ordem e equilíbrio ocorre quando se busca explicar a sua existência a partir de um modelo de comportamento individual dado e com base num "estado de natureza" inicial, livre de instituições. "The procedure is to start with given individuals and to move on to explain institutions" (HODGSON, 1998, p. 181).

Diante disso, tem-se que o objetivo da NEI está em explicar o surgimento das instituições a partir das interações entre indivíduos de racionalidade pré-definida, enquanto os processos condicionantes são deixados de lado na análise. Esta abordagem enfrenta críticas em decorrência do uso do individualismo metodológico. Field (1984) aponta os erros da tentativa da NEI e dos autores da teoria dos jogos em tentar explicar a origem das instituições a partir de indivíduos dados. Para o autor, o pressuposto da existência de um ponto de partida livre de instituições é problemático. Não há como a realização de jogos sem regras previamente estabelecidas. Esta questão recai sobre o problema da regressão infinita, no qual em jogos sequenciais há sempre um jogo precedente a ser explicado, o qual contribui para a definição das circunstâncias e resultados do jogo seguinte (HODGSON, 1998). Logo, tendo estes modelos partindo do princípio comportamental de maximização do interesse próprio, e se deseja modelar ordens sociais estáveis, é necessário postular regras ou normas desde os primeiros estágios da interação para que, assim, se possa definir as restrições e o cenário no qual a maximização ocorre.

Considerando a impossibilidade de explicar o sistema partindo apenas de indivíduos de racionalidade preestabelecida, se argumenta que o contexto institucional importa em qualquer período do tempo e que, portanto, deve ser explicado por outros métodos além do individualismo metodológico.

Recognizing that norms need to be analyzed in their own right, using extraeconomic and often case-specific methods, one can redefine microeconomic analysis as the analysis of the results of behavior by selfinterested agents acting within constraints determined in part by technologies, resources, and the preference of others, but also in part by the systems of rules or norms confronted (in the sense that they constrain the 
behavior of others) or participated in (in the sense that they influence individual behavior irrespective of others' behavior). Any outcomes predicted or explained by such behavioral models are as conditional on the specified 'social restraints' (norms) as they are on the other more commonly specified categories of exogenous variables (FIELD, 1984, p. 704).

A tentativa de endogeneizar as instituições dentro do arcabouço neoclássico implica em uma interpretação das instituições e da mudança institucional como um processo derivado de decisões individuais otimizadoras que operam face às mudanças tecnológicas, demográficas e de outras restrições exogenamente determinadas (RUTHERFORD, 1994). Neste contexto, North e Robert Thomas, em trabalho de 1973, tiveram algumas dificuldades para adaptar a abordagem da NEI no intuito de analisar a mudança histórica. Para Field (1981), o conservadorismo institucional fez com que os autores tivessem que abandonar a explicação das instituições e da mudança institucional com base no modelo da busca pela eficiência. North e Thomas (1973) admitiram que as instituições existentes atuam restringindo a mudança institucional adicional requerida para direcionar o sistema para um nível de maior eficiência.

(...) in explaining this important aspect of the historical record, the authors wreak havoc with their research objective. Because, if they can, at will, make appeal to this conservative principle to explain why a set of expectations (in this case, 'traditions, the governing law of the manor') are not challenged, then the implicit model of institutional change is shattered. The modified version becomes: institutions change in response to underlying parameter shifts, except when they do not, that is, except when conservative principles prevail. This is, to put it mildly, a less general model (FIELD, 1981, p. 190).

A percepção da existência de inércia institucional fez North rever a sua posição. Já na obra de 1990 o autor abandona a abordagem da eficiência para a explicação das instituições e da mudança institucional. Desta forma, North (1990) passou a ver a evolução institucional como path dependence. Ou seja, as instituições, na visão do autor, não podem ser concebidas endogenamente a partir dos modelos neoclássicos, sendo que a história importa para explicar a dotação institucional das sociedades. Assim, a compreensão de qualquer mudança institucional terá de ser analisada a partir de indivíduos imersos em um contexto formado por instituições preexistentes, como dadas (RUTHERFORD, 1994). 
A análise de North (1990) torna clara a importância da ideologia e da percepção, concebidas a partir da cultura e dos hábitos, para explicar desvios do comportamento racional da teoria neoclássica. "Não conheço um modo de explicar o término da escravidão no século XIX que não leve em conta a mudança da percepção sobre a legitimidade de que alguém tenha posse de outrem." (p. 49). Porém, conforme afirma Rutherford (1994), o autor não fornece uma teoria para explicar endogenamente a mudança e a estabilidade institucional, de modo que isto é exogenamente determinado. Logo, a partir destas considerações, conclui-se que "North's program of successive endogenization is likely to remain incomplete" (RUTHERFORD, 1994, p. 46).

Por fim, tem-se que a noção de indivíduos em Veblen impede uma abordagem de equilíbrio uma vez que a interação entre agente e instituições é caótica e evolucionária. Aqui os indivíduos estão em constante transformação, podendo a função objetivo - que nos escritos de Veblen se configura a partir das inclinações instintivas - ser alterada a partir das experiências vivenciadas pela sociedade. Como consequência, o problema da economia vebleniana é distinta da NEI. Em vez de se discutir questões acerca do arranjo institucional requerido para a otimização dos resultados, a preocupação de Veblen é propriamente os objetivos humanos por si só. É a partir destes que o autor desenrola sua análise sobre os rumos tomados pela sociedade como um todo, sendo tais objetivos explicados a partir de um sistema complexo envolvendo o ambiente material, institucional e as inclinações inerentes à natureza humana.

Já em relação à abordagem da EPI, os escritos veblenianos apresentam diferenças mais sutis no campo da teoria, mas completamente dissonantes no que se refere às interpretações de política econômica. Vejamos a seguir como isso se estabelece no debate institucionalista.

\subsection{Convergências e divergências entre as abordagens institucionalistas de Veblen e Chang}

Para Hodgson (2004), os instintos são elementos importantes utilizados por Veblen para explicar a inércia ou a mudança institucional. Isto é coerente com a ideia de que as instituições, por estarem presentes num nível de complexidade distinto da natureza humana, não apresentam os mecanismos sensitivos que se encontram na fisiologia humana para avaliar a necessidade de mudança ou continuidade. Ou seja, é na mente dos agentes que se encontram as emoções e desejos que ditam as regras para a ação institucional. Para Cavalieri (2009), a economia política de Veblen confere a categoria dos 
instintos importância maior do que as próprias instituições. Consequentemente, como será discutido a seguir, a incorporação da teoria vebleniana da natureza humana no debate institucionalista sobre o desenvolvimento econômico e social tem implicações teóricas que podem levar a interpretações distintas em relação às abordagens da NEI e da EPI.

Embora a literatura considere a abordagem da EPI próxima dos escritos de Veblen ${ }^{5}$, em especial no que tange a noção de instituição e a ideia de causação circular entre indivíduo e instituições, se pode argumentar que os autores do grupo liderado por Chang dão um foco maior às instituições quando comparados com o próprio pai do institucionalismo.

O ponto a ser discutido é que, levando em conta os escritos veblenianos, a mudança institucional por si só não é condição suficiente para a mudança de trajetória das sociedades. A compreensão das trajetórias de desenvolvimento não é apenas uma questão de análise das instituições. Há também informações importantes nas inclinações humanas que são fundamentais para compreender a configuração e mudança institucional. A tipificação feita por Veblen das inclinações humanas que afetam a atividade econômica, como os instintos para o artesanato e predatório, permite compreender o sentido das instituições informais e os mecanismos que atuam habilitando ou inibindo a ação das instituições formais.

Para o autor, a contaminação do instinto para o artesanato por propensões predatórias fez emergir instituições "imbecis" - citando a ascensão do Cristianismo - que inibiram as ações e hábitos baseados no trabalho eficaz e que contribuíram para o avanço tecnológico. Logo, na visão de Veblen não são as instituições, mas a inclinação instintiva o motor fundamental para a explicação da trajetória de desenvolvimento.

Isso não quer dizer que as instituições não importam e sim que este elemento por si só é insuficiente para explicar a mudança e o sentido da sociedade. As instituições são essenciais pois fazem parte do ambiente sobre o qual os indivíduos interagem e têm suas inclinações instintivas afloradas. Porém, os mecanismos sensitivos que definem os objetivos a serem perseguidos não estão nas instituições e sim nos instintos.

Neste sentido, pode-se argumentar que o processo de ajustamento institucional somente pode ser compreendido à luz das propensões humanas. Como visto no capítulo

\footnotetext{
${ }^{5}$ Para Grazziotin, Avila e Herrlein (2015) o marco teórico da EPI construído a partir das análises de Ha-Joon Chang acerca das instituições e tem como base um pensamento contemporâneo baseado na compatibilização da visão do "Velho Institucionalismo" de Veblen e John Commons com a de outros autores de Economia Política, como Karl Marx e Joseph Schumpeter.
} 
anterior, são os instintos que desencadeiam os processos cognitivos responsáveis pela formação dos hábitos. Nas palavras do autor institucionalista "Men take thought, but the human spirit, that is to say the racial endowment of instinctive proclivities, decide what they will take thought of, and how to what effect" (VEBLEN, 1914, p. 6). Os instintos são, portanto, a base para a configuração institucional, sendo a categoria a responsável por estabelecer o sentido das instituições e as decisões de mudança ou manutenção dos hábitos mentais enraizados socialmente.

Diante disto, considera-se neste artigo que a questão a ser tratada pelo institucionalismo não é sobre o ajustamento entre instituições formais e informais, como estabelecido pela EPI, mas a dinâmica entre instituições e inclinações humanas. Para Veblen (1914), os hábitos e instituições concebem as formas encontradas pelos indivíduos para realizar os objetivos propostos pela carga instintiva. Podemos sumarizar a mudança institucional como desencadeada por um desajustamento entre instituições e os instintos aflorados. Tal processo pode ser iniciado de duas maneiras: 1) quando as instituições vigentes não forem mais aptas para a realização das propensões dominantes ou 2) quando um novo conjunto de propensões passa a ser aflorado por novas experiências enfrentadas pelos indivíduos.

Em ambos os casos, a mudança institucional é invocada quando ocorrem mudanças no ambiente material ou social, de modo que novas formas de agir e pensar se tornam necessárias para a realização das propensões humanas. O que faz esta mudança de ambiente ser um pontapé na alteração dos rumos na trajetória de desenvolvimento social de um povo é se as novas experiências resultantes do novo contexto podem ou não aflorar um conjunto de propensões distintas do que era vigente. Isto está retratado na análise de Veblen sobre a história da evolução das sociedades humanas.

Para Veblen, em cada fase da humanidade o ponto de destaque da análise são os instintos aflorados pelas experiências que as sociedades vivenciaram, enquanto as instituições, mesmo que apresentando certas semelhanças, como é o caso da propriedade privada, tiveram formas mais diversas. Assim, são os instintos que configuram o sentido da trajetória de desenvolvimento de cada fase. Para o autor, o determinante fundamental da capacidade de progresso material e de bem-estar de um povo é as inclinações instintivas que dominam as ações dos agentes em geral. Cabe às instituições habilitarem as ações compatíveis com os instintos que lhes servem de base, enquanto restringe as inclinações opostas. 
Isso fica evidente na explicação do autor para o avanço das instituições de cunho predatório que passaram a inibir a velocidade das inovações tecnológicas, cujo movimento tinha como base as instituições ligadas ao instinto para o trabalho eficaz. "Innovation, the utilization of newly acquired technological insight, is greatly hindered by such institutional requirements that are enforced by other impulses than the sense of workmanship" (VEBLEN, 1914, p. 41-42).

Veblen $(1898,1914)$, ao longo de seus escritos, identificou algumas fases da história humana que podem ser diferenciadas pelas propensões dominantes que direcionam as instituições. A primeira fase seria a da "selvageria pacífica", cujo aspecto mais evidente seria seu caráter pacífico e a predominância do comportamento solidário, condizente com a dominância do instinto para o artesanato como força principal na orientação das ações e visões de mundo das sociedades (VEBLEN, 1914). Posteriormente viria a "fase predatória", a qual é derivada do sucesso da fase anterior. Os aumentos constantes de produtividade devido às ações com base no instinto para o trabalho eficaz fizeram com que excedentes produtivos passassem a vigorar nas sociedades. Assim, pela primeira vez, passou a existir a questão da posse dos bens excedentes. Se antes tudo era consumido, no novo cenário de afluência algum destino deveria ser dado às sobras do processo produtivo. Inicialmente, tais excedentes ficavam nas mãos da coletividade, mas com o tempo foi-se aflorando a inclinação predatória humana, de modo que a possibilidade de um novo destino para estes excedentes passou a ser considerado, dando espaço para uma nova configuração institucional (CAVALIERI, 2009).

A fase pecuniária pode ser dividida em "barbárie", ou fase "pecuniária predatória" e a fase "pecuniária pacífica". Na primeira, o aumento da capacidade produtiva permitiu que uma parcela dos indivíduos pudessem se abster do trabalho serviu e se aventurasse em atividades que visassem grandes feitos, como a caça e a guerra. Assim, os indivíduos eram comparados entre si pela capacidade de infligir danos e perdas aos inimigos. Já a fase pecuniária pacífica representa a ampliação da posse individual das coisas, cujo hábito passou a ser institucionalizado, legitimando a propriedade individual como traço essencial da convivência social (CAVALIERI, 2009).

Até aqui não há fortes implicações que permitam utilizar a abordagem da teoria dos instintos de Veblen para invalidar os avanços da EPI. O esquema proposto pela teoria dos instintos mantém a incerteza da mudança institucional sobre a trajetória do sistema. O mesmo se verifica na abordagem de Chang (2007), sobre o ajustamento entre instituições formais e informais, quando afirma que uma mesma instituição presente em diversas 
sociedades pode apresentar distintas funções dependendo da interação que se estabelece com as demais instituições locais.

Outro ponto de tangência entre as abordagens é que a capacidade das instituições de moldar indivíduos é chave tanto no institucionalismo vebleniano quanto na abordagem da EPI. Em ambos, é comumente reconhecido que os agentes tomam para si os valores morais e os objetivos materializados na estrutura institucional. A diferença é que a teoria dos instintos de Veblen vê as propensões inatas à fisiologia humana como elementos definidores destes valores e objetivos presentes nas instituições e que, portanto, dá a estas categorias instintivas certo protagonismo que para a EPI é exclusivo das instituições.

A principal distinção entre estas abordagens fica por conta da questão sobre os limites e possibilidades da instituição de processos deliberados de mudança. A EPI reconhece a intenção e a posição ativa dos indivíduos responsáveis pela execução de instituições formais, de modo que a mudança institucional é feita de forma deliberada, visando um fim desejado. Já para Veblen a mudança institucional segue uma trajetória indefinida, cega e não teleológica.

Em linha com o pensamento vebleniano, a mudança econômica e social ocorre com base nas alterações dos hábitos e instintos, pois é somente a partir destes que um novo conjunto de instituições podem se perpetuar. Ao contrário da EPI, para Veblen (1914) a mudança é direcionada não por transformações institucionais deliberadas, mas pelas propensões afloradas por novas circunstâncias, derivadas de transformações na estrutura material e/ou institucional.

É importante enfatizar que mudanças na estrutura tecnológica e/ou das instituições formais atuam apenas como impulsoras de uma série de processos que poderão ou não levar à mudança nas instituições informais. Este choque inicial, para Veblen, tem pouco poder para controlar a direção das transformações subsequentes. A incerteza está no desconhecimento do tipo de inclinação instintiva a ser aflorada pelas experiências fornecidas pelo novo ambiente. Dado a modificação da estrutura, a chamada para as alterações nos hábitos vigentes requeridos para a perseguição dos objetivos listados pelas inclinações dominantes pode ou não implicar em mudança nas propensões atuantes na mente da sociedade. Para isto, dependerá do tipo de adaptação realizada pelos hábitos, os quais poderão manter a realização dos objetivos definidos pela carga instintiva ou evocar uma redefinição desta.

Desta forma, pode-se definir o esquema vebleniano da seguinte forma: (1) alterações do ambiente material e institucional levará a mudanças nas experiências vividas pela 
sociedade, (2) impactando diretamente os hábitos dos indivíduos que, por sua vez, (3) serão reavaliadas pelas inclinações vigentes, levando estas a se manterem ou se modificarem, (4) cujo resultado final são transformações indefinidas e incertas nas instituições como um todo.

Isso não quer dizer que Veblen não concordava com o papel constitutivo das instituições, mas que a relação entre estas e os indivíduos é multidirecional, podendo os últimos também determinarem as instituições. Esta relação é orgânica e simbiótica, e não determinista. Em linha com o autor, o resultado de um choque nas instituições formais será derivado das relações entre estas instituições e os hábitos e instintos dominantes. O papel constitutivo das instituições não é exercido de forma direta, mas sim a partir da avaliação pelas inclinações instintivas que imperam a mente dos agentes de uma sociedade e, consequentemente, da reconfiguração dos hábitos que dirigem o comportamento humano.

Under given circumstances and under the impulsion of a given instinctive propensity a given line of behavior becomes habitual and so is installed by use and wont as a principle of conduct. The principle or canon of conduct so gained takes its place among the habitual verities of life in the community and is handed on by tradition (VEBLEN, 1914, p. 50).

É importante ter em mente que Veblen e Chang tiveram objetivos diferentes em seus escritos. O primeiro institucionalista não via com bons olhos a engenharia social e a concepção da teoria econômica orientada fundamentalmente para propósitos práticos e ativistas (RUTHERFORD, 1994). Enquanto a EPI concentra a maior parte de seus escritos na construção de um arcabouço teórico para justificar políticas econômicas desenvolvimentistas, Veblen teve maior preocupação em definir os mecanismos que determinam o comportamento humano e suas transformações ao longo da história.

Em The place of science in modern civilization, Veblen (1906) associou a atividade científica com a propensão da curiosidade desinteressada e que, portanto, para a sua prática ser realizada de forma eficiente deveria ser isenta de valores e objetivos além do conhecimento altruísta. Por outro lado, reconheceu que tal inclinação era passiva de contaminação pelo instinto para o trabalho eficaz, cuja principal característica é a perseguição de propósito útil.

Pragmatism creates nothing but maxims of expedient conduct. Science creates nothing but theories. It knows nothing of policy or utility, of better or worse. (...) Wisdom and proficiency of the pragmatic sort does not contribute to the advance of a knowledge of fact. It has only an incidental bearing on 
scientific research, and its bearing is chiefly that of inhibition and misdirection. Wherever canons of expediency are intruded into or are attempted to be incorporated in the inquiry, the consequence is an unhappy one for science, however happy it may be for some other purpose extraneous to science. The mental attitude of worldly wisdom is at cross-purposes with the disinterested scientific spirit, and the pursuit of it induces an intellectual bias that is incompatible with scientific insight (VEBLEN, 1906, p. 19).

Embora Veblen tenha sido um crítico das instituições dominantes de sua época, evitou sugerir reformas ou se envolver com organizações que lutavam em favor da mudança institucional. Segundo Dorothy Ross (1992, p. 213) "Veblen wanted science to provide critical insight into the course of evolution, not become a tool to control it." Para Tilman (1984), esta atitude contrasta fortemente com os demais autores da corrente dos velhos institucionalistas que apresentavam uma visão mais reformista, como Mitchell, Commons e Ayres.

Neste grupo de reformistas é coerente também a incorporação da corrente institucionalista de Chang, pois o autor foca diretamente no tema de política econômica. Em termos gerais, os trabalhos do expoente da EPI têm como intuito empregar os princípios da teoria institucionalista para contrapor o receituário neoliberal. O intuito não é estabelecer um plano detalhado de ação, pois isto iria contra os princípios da própria abordagem institucionalista heterodoxa. Ou seja, argumenta-se em prol de um método histórico, no qual as instituições importam, mas estabelecem uma relação complexa e não linear com o desenvolvimento econômico. Entretanto, fica claro que Chang (2002, 2004a, 2004b) defende o uso de políticas ativas por parte do Estado para a proteção e promoção de atividades ligadas à inovação, ciência e tecnologia.

Chang (2004a) afirma que a mudança tecnológica requer uma coordenação planejada e centralizada pela instituição do Estado, em vez de baseada na coordenação descentralizada do mercado. A capacidade coordenadora do Estado está associada à capacidade constitutiva das instituições. Assim, o Estado pode baixar os custos que envolvem os investimentos desejados ao fornecer um "ponto focal" ou uma "visão comum" aos agentes do setor privado. Para isto, cabe ao Estado garantir boas condições de negócios, gerir os conflitos e compensar possíveis perdas das firmas que resolverem adotar novas tecnologias e processos produtivos mais sofisticados. Dentre os mecanismos estão a concessão de subsídios, a criação de barreiras protecionistas contra os importados, 
fornecimento de crédito subsidiado, a formação de mão-de-obra especializada e conhecimento científico, através das universidades e institutos de pesquisa e inovação. Além disso, é papel dos governos garantir a demanda para os produtos das firmas inovadoras, seja através da ampliação do mercado interno ou via expansão fiscal (CHANG, 2002).

Desta forma, Chang se torna o principal expoente na defesa do Estado Desenvolvimentista como instituição capaz de promover o desenvolvimento econômico nos países de industrialização tardia. Embora o autor argumente sobre a inexistência de consenso acerca do formato e das funções que as instituições devem apresentar, a discussão da importância destes aspectos permanece relevante na maioria dos seus escritos (GRAZZIOTIN, ÁVILA \& HERRLEIN,2015).

As diferenças entre a abordagem vebleniana e a da EPI podem parecer sutis, dando a impressão de que a incorporação na teoria dos instintos implicará em poucas mudanças no arcabouço teórico institucionalista, como também na recomendação de política econômica. Porém, os resultados podem ser significativos quando se avalia as interpretações acerca do sistema capitalista de produção realizado por Veblen em seus últimos trabalhos, os quais têm como base a teoria dos instintos.

Em alguns momentos, como na obra The engineers and the price system (1921), o autor condena políticas governamentais que beneficiam o setor industrial. Nesta, argumenta-se que políticas com propósito no aumento da utilização dos recursos industriais de um país têm como implicação indireta o desperdício e a baixa eficiência. Esta visão é estranha à EPI e à heterodoxia econômica, porém é coerente com o arcabouço do institucionalismo vebleniano e sua posição no debate norte-americano da época.

Por fim, é importante deixar claro que as divergências levantadas neste trabalho sobre as abordagens teóricas de Veblen e Chang não visam invalidar as contribuições teóricas e práticas da EPI. Muito pelo contrário. O objetivo aqui é unicamente o de encontrar lacunas que, embora causem certo prejuízo aos méritos da teoria, são totalmente passíveis de serem superadas a partir da incorporação das críticas levantadas.

Essa sobreposição se faz necessária uma vez que tanto Veblen quanto Chang focaram em objetos de análise distintos. Veblen foi um autor que deu ampla importância aos fundamentos das instituições e da natureza humana para entender os conflitos inerentes ao capitalismo. Já Chang se preocupou com o impacto das especificidades institucionais nas trajetórias de desenvolvimentos dos países. 
Ou seja, podemos inferir que, se de um lado, Chang não foi necessariamente um teórico das instituições, por outro, Veblen não apresentou um esboço sistematizado sobre as trajetórias institucionais, que foi algo que ocupou bastante o arcabouço da EPI.

Sendo assim, acredita-se que essa sobreposição entre as correntes institucionalistas abre margem para que avanços importantes sejam alcançados, permitindo novas interpretações dos fenômenos socioeconômicos como também a consideração de perspectivas que até então eram ignoradas na idealização de receituários práticos de políticas para o desenvolvimento econômico.

\section{CONSIDERAÇÕES FINAIS}

O marco principal de qualquer uma das diferentes abordagens institucionalistas - 0 antigo institucionalismo de Veblen, a NEI de North, a EPI de Chang, o neo-institucionalismo de Hodgson - é de que as instituições importam para a explicação da sociedade e de suas respectivas trajetórias de desenvolvimento. Entretanto, não há consenso sobre os impactos das instituições no desenvolvimento e nem sobre qual o melhor arranjo institucional para a promoção de trajetórias desejadas. A sistematização entre instituições e desenvolvimento depende não apenas do próprio conceito de instituição, mas também de indivíduo, os quais são tratados de forma distintas entre as correntes citadas.

Pela NEl, é reconhecido que os indivíduos são dotados de capacidade cognitiva preestabelecida e imutável, o qual serve de base para o ajustamento das instituições. A associação destas como fonte de ordem e equilíbrio ocorre quando se busca explicar a sua existência a partir de um modelo de comportamento individual dado e com base num "estado de natureza" inicial, livre de instituições. Logo, o objetivo da abordagem de North é o de explicar o surgimento das instituições a partir das interações entre indivíduos de racionalidade pré-definida, enquanto os processos condicionantes são deixados de lado na análise.

Já a noção de indivíduos em Veblen impede uma abordagem de equilíbrio uma vez que a interação entre agente e instituições é caótica e evolucionária. Nela os indivíduos estão em constante transformação, podendo a função objetivo - que nos escritos de Veblen se configura a partir das inclinações instintivas - ser alterada a partir das experiências vivenciadas pela sociedade. Como consequência, o problema da economia vebleniana é distinta da NEI. Em vez de se discutir questões acerca do arranjo institucional requerido para a otimização dos resultados, a preocupação de Veblen é propriamente os objetivos 
humanos por si só. É a partir destes que o autor desenrola sua análise sobre os rumos tomados pela sociedade como um todo, sendo tais objetivos explicados a partir de um sistema complexo envolvendo o ambiente material, institucional e as inclinações inerentes à natureza humana.

A dissonância entre Veblen e a EPI é mais sutil. A principal distinção entre estas fica por conta da questão sobre os limites e possibilidades da instituição de processos deliberados de mudança. A EPI reconhece a intenção e a posição ativa dos indivíduos responsáveis pela execução de instituições formais, de modo que a mudança institucional é feita de forma deliberada, visando um fim desejado. Já para Veblen a mudança institucional segue uma trajetória indefinida, cega e não teleológica.

Em linha com o autor, a mudança econômica e social ocorre com alterações nos instintos, pois é somente a partir destes que um novo conjunto de instituições podem se perpetuar. Ao contrário da EPI, para Veblen (1914) a mudança é direcionada não por transformações institucionais deliberadas, mas pelas propensões afloradas por novas circunstâncias, derivadas de transformações na estrutura material e/ou institucional.

$\mathrm{Na}$ estrutura teórica vebleniana as mudanças na estrutura tecnológica e/ou das instituições formais atuam apenas como impulsoras de uma série de processos que poderão ou não levar à mudança nas instituições informais. Este choque inicial, para Veblen, tem pouco poder para controlar a direção das transformações subsequentes. A incerteza está no desconhecimento do tipo de inclinação instintiva a ser aflorada pelas experiências fornecidas pelo novo ambiente. Dado a modificação da estrutura, a chamada para as alterações nos hábitos vigentes requeridos para a perseguição dos objetivos listados pelas inclinações dominantes pode ou não implicar em mudança nas propensões atuantes na mente da sociedade. Para isto, dependerá do tipo de adaptação realizada pelos hábitos, os quais poderão manter a realização dos objetivos definidos pela carga instintiva ou evocar uma redefinição desta.

Por fim, tendo em mente as distinções teóricas analisadas neste paper, acredita-se que o resgate e incorporação das ideias veblenianas originais no debate entre as modernas abordagens institucionalistas se configura como uma importante linha de pesquisa institucionalista, podendo apresentar implicações importantes nas interpretações das trajetórias históricas de desenvolvimento, como também nas discussões sobre recomendações de política econômica, incluindo os princípios que envolvem o paradigma do Estado Desenvolvimentista. 


\section{REFERÊNCIAS}

BALASSA, B. Development strategies and economic performance, in Balassa, B. et al., Development Strategies in Semi-Industrial Economies, Baltimore, Maryland, The Johns Hopkins University Press, 1982.

CAMPOS, M. O Processo de Desenvolvimento Econômico a Partir de Uma Perspectiva Institucionalista: Elementos de Uma Abordagem Heterodoxa. Tese (Doutorado em Economia) - Programa de Pós-Graduação em Economia da Faculdade de Ciências Econômicas da UFRGS, Universidade Federal do Rio Grande do Sul, Porto Alegre), 2016

CAVALIERI, M. A. O surgimento do institucionalismo norte-americano: um ensaio sobre o pensamento e o tempo de Thorstein Veblen, Tese de doutorado, Programa de Pós-graduação em Economia, CEDEPLAR/UFMG), 2009.

CHANG, H. J. The political economy of industrial policy. St. Martin's Press, 1994.

CHANG, H. J. An Institutionalist Perspective on the Role of the State-Towards an Institutionalist Political Economy. Institutions and the Role of the State, 3-26, 2000.

CHANG, H. J., CHEEMA, A., \& MISES, L. Conditions for successful technology policy in developing countries - Learning rents, state structures, and institutions. Economics of Innovation and New Technology, 11(4-5), 369-398, 2002.

CHANG, H. J. Chutando a escada. Unesp, 2004a

CHANG, H. J. Institutional foundations for effective design and implementation of selective trade and industrial policies in the least developed countries: theory and evidence.

Globalization, economic development and the role of the State. London: Zed Books, 2004b.

CHANG, H. J., \& EVANS, P. The role of institutions in economic change. Reimagining growth: towards a renewal of development theory, 99-129, 2005.

CHANG, H. J. Institutional change and economic development: An introduction. Institutional change and economic development, 1-14, 2007.

COASE, R. The Institutional Structure of Production. American Economic Review. 82:4, pp. 713-19, 1992.

CONCEIÇÃO, O. A. C. Os antigos, os novos e os neo-institucionalistas: há convergência teórica no pensamento institucionalista? Análise Econômica, Porto Alegre, v. 19, n. 36, p. 25-45, 2001.

CONCEIÇÃO, O. A. C. A relação entre processo de crescimento econômico, mudança e instituições na abordagem institucionalista. Ensaios FEE, Porto Alegre, v. 23, p. 603-620, 2002. 
COMMONS, J. R. Legal Foundations of Capitalism. New York: Macmillan, 1924.

EPSTEIN, G. Central banks as agents of economic development (No. 2006/54). Research Paper, UNU-WIDER, United Nations University (UNU), 2006.

FIELD, A. J. Microeconomics, norms, and rationality. Economic Development and Cultural Change, 32(4), 683-711, 1984.

GRAZZIOTIN, H. D. A.; AVILA, R. I.; HERRLEIN JR, R. A Economia Política Institucionalista e o desenvolvimento. In: DATHEIN, R. (Org.). Desenvolvimentismo: o conceito, as bases teóricas e as políticas. Porto Alegre: Editora da UFRGS. p. 113156, 2015.

HODGSON, G. M. The approach of institutional economics. Journal of economic literature, 36(1), 166-192, 1998.

HODGSON, G. M. John R. Commons and the foundations of institutional economics. Journal of Economic Issues, 37(3), 547-576, 2003.

HODGSON, G. M. The evolution of institutional economics. Routledge, 2004.

JAMES, W. The Principles of Psychology, 2 vols, 1st edn (New York and London: Holt and Macmillan), 1890.

JAMESON, K. Has Institutionalism Won the Development Debate? Journal of Economic Issues, Sacramento, v. 40, n. 2, p. 369-375, 2006.

LAL, D. The Poverty of Development Economics, London, The Institute of Economic Affairs, 1983.

LITTLE, I. Economic Development, New York, Basic Books, 1982.

MCDOUGALL, W. An introduction to social psychology. London: Methuen, 1950. First published, 1908.

NELSON, R. Recent Evolutionary Theorizing About Economic Change. Journal of Economic Literature, Nashville, v. 33, p. 48-90, 1995.

NORTH, D.; THOMAS, R. P. The Rise of Western World: A New Economic History. Cambridge: Cambridge University Press, 1973.

NORTH, D. Institutions, institutional change and economic performance. Cambridge University Press. New York, 1990.

NORTH, D. Economic Performance Through Time. The American Economic Review, Nashville, v. 84, No. 3, 1994.

NORTH, D. Understanding the Process of Economic Change. Princeton: Princeton University Press, 2005. 
POLANYI, K. A grande transformação: as origens políticas e econômicas do nosso tempo. Rio de Janeiro: Elsevier, 2012.

ROSS, D. The origins of American social Science. Cambridge University Press, 1992.

RUTHERFORD, M. Institutions in economics: The old and the new institutionalism. Cambridge: Cambridge University Press, 1994.

SCHOTTER, ANDREW. The economic theory of social institutions. Cambridge: Cambridge U. Press, 1981.

TILMAN, R. Dewey's Liberalism vs. Veblen's Radicalism. Journal of Economic Issues. 28 (September): 745-69, 1984.

VEBLEN, T. The instinct of workmanship and the irksomeness of labor. American Journal of Sociology, 4(2), 187-201, 1898.

VEBLEN, T. The Place of Science in Modern Civilization. The American Journal of Sociology, Vol. XI, 1906.

VEBLEN, T. The Instinct of Workmanship, and the State of the Industrial Arts, New York, Augustus Kelley, 1914.

VEBLEN, T. The Place of Science in Modern Civilization and Other Essays. New York: B. W. Huebsch, 1919.

VEBLEN, T.The engineers and the price system. BW Huebsch, Incorporated, 1921.

VEBLEN, T. A teoria da classe ociosa: um estudo econômico das instituições. São Paulo: Abril Cultural, 1987.

WILLIAMSON, O. Markets and Hierarchies. New York: Free Press, 1975.

WILLIAMSON, O. The new institutional economics: taking stock, looking ahead. Journal of economic literature, 38(3), 595-613, 2000.

ZYSMAN, John. How Institutions Create Historically Rooted Trajectories of Growth. Industrial And Corporate Change, 3(1):243-283, 1994. 